\title{
Comparación Regional de Leyes en materia de Precios de transferencia Centroamérica y Panamá
}

\author{
Por Audit \& Tax services S.A de C. V
}

n los últimos años se han aprobado leyes e instructivos en la región centroamericana y Panamá para regular el mecanismo conocido como "Precios de transferencia", que se emplea en transacciones entre compañías vinculadas o entre partes relacionadas. De ahí que en países como El Salvador, Panamá, Honduras, Nicaragua, Costa Rica y Guatemala, se encuentran vigentes, en este momento, Leyes y/o mecanismos normativos sobre el tema, todos ellos basados en los lineamientos de la Organización para la Cooperación y el Desarrollo Económico (OCDE) que contempla una metodología para la comprobación de los precios de transferencia, cuya aplicación ha sido acogida, ampliamente, en el contexto internacional.

Con base en este marco jurídico, los sujetos comprendidos en dicha normatividad están obligados a presentar, además de las declaraciones anuales del Impuesto sobre la renta, información complementaria según lo requiera la legislación de cada país con el detalle de

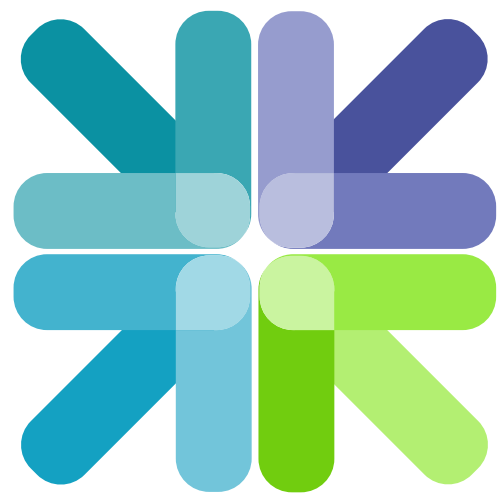

las distintas transacciones llevadas a cabo entre empresas vinculadas o partes relacionadas que involucran diferentes tipos de análisis, de carácter técnico, económico, financiero y comercial, de los precios de transferencia.

Asimismo, la regulación sobre el tema contempla la obligación de conservar los comprobantes y demás documentación que justifique los precios de transferencia consignados en la declaración informativa, los métodos empleados en la determinación de los mismos y los criterios de comparación utilizados para concluir que el método empleado resulta el más apropiado para la operación.

Por estos motivos, y por tratarse de un tema complejo y relativamente nuevo en el área Centroamericana y Panamá, consideramos de gran importancia el que se pueda conocer los tópicos de la legislación relativa a la temática en cada uno de los países de la región, según el orden de vigencia.

\section{PANORAMA DE LA REGIÓN}
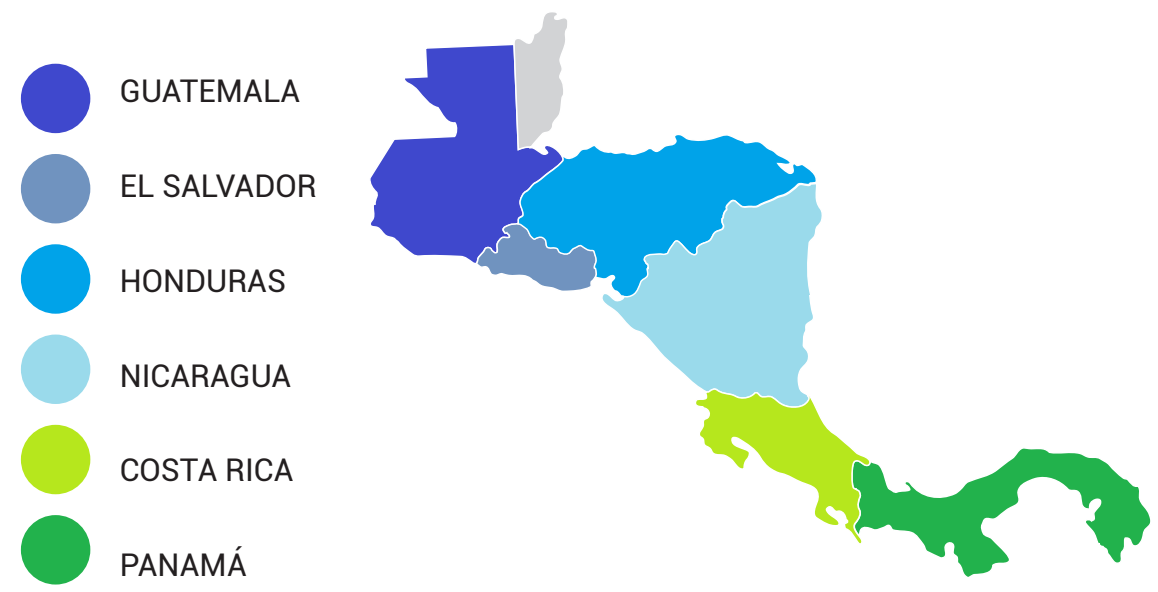

\begin{tabular}{ccccccc} 
& 2011 & & 2013 & & 2015 & \\
\hline 2010 & 0 & 2012 & & 2014 & $\bigcirc$ & 2016
\end{tabular}




\section{MARCO REGULATORIO}

\section{EL SALVADOR}

Durante el mes de diciembre de 2009 mediante el Decreto Legislativo No. 223, se introdujeron en el Código Tributario, algunos aspectos relativos a la determinación de precios como parte de los hechos generadores contenidos en dicho Código. Asimismo, el mes de marzo 2012, se emitió por porte de la Dirección General de Impuestos Internos la Guía DG-001/2012 relativa a "Guía de orientación General para facilitar el tratamiento con sujetos relacionados o con sujetos domiciliados, constituidos o ubicados en países, estados o territorios de régimen fiscales preferentes, de baja o nula tributación o paraísos fiscales".

\section{PANAMA}

Con la aprobación de la Ley 33, del 30 de junio de 2010 publicada en la Gaceta Oficial No. 26566-A que regula entre otras materias el régimen de Precios de Transferencia en la República de Panamá. De igual forma, la modificación a esta por La Asamblea Nacional, mediante la aprobación del proyecto de Ley 491, se introdujeron elementos importantes a resaltar respecto a dicha disposición, derivado de lo antes descrito, el Artículo 762-D del Código Fiscal contempla el Ámbito de Aplicación de la norma, estableciendo lo siguiente:

"...El ámbito de aplicación de las disposiciones legales a que se refiere el párrafo anterior alcanza a cualquier operación que un contribuyente realice con partes relacionadas que sean residentes fiscales de otras jurisdicciones, siempre y cuando dichas operaciones tengan efectos como ingresos, costos o deducciones en la determinación de la base imponible, para fines del Impuesto sobre la Renta, del período fiscal en el que se declare o lleve a cabo la

\section{GUATEMALA}

La legislación de Precios de Transferencia en Guatemala, se encuentra establecida en el Decreto 10-2012 que incluye la incorporación de obligación de valuar las operaciones entre partes relacionadas a valor de mercado, el decreto entró en vigencia el $1^{\circ}$ de enero de 2013. Los requerimientos de precios de transferencia son aplicables a cualquier operación llevada a cabo entre un contribuyente residente en Guatemala y una parte relacionada no residente, siempre y cuando dicha operación tenga efectos en la determinación de la base imponible del período en el que se realiza la operación y en los siguientes.

Además, el 8 de mayo de 2013 la SAT emitió el acuerdo el Acuerdo Gubernativo 213-2013, el cual contiene el Reglamento de la Ley de Actualización Tributaria para la Ley de Impuesto sobre la Renta, con el cual entre otras cosas refuerza y reglamenta la legislación en materia de precios de transferencia.

La Ley de Impuesto sobre la Renta, en lo relativo a precios de transferencia establece que los contribuyentes al momento de la presentación de su Declaración del Impuesto sobre la Renta Corporativo, deben contar con la información y análisis suficiente para demostrar y justificar la correcta determinación de precios, los importes de los pagos efectuados o los márgenes de beneficios en sus transacciones con partes relacionadas de acuerdo con el "Principio de Libre Competencia"

\section{HONDURAS}

Mediante decreto 233-2011, publicó en la Gaceta en fecha 10 de diciembre 2011, la "Ley de Regulación de Precios de Transferencia", que entró en vigencia el 10 de diciembre de 2010 y entrará efectivamente a ser aplicada para el período fiscal del 2014.

Su ámbito de aplicación alcanza a cualquier operación que realicen las personas naturales o jurídicas domiciliadas o residentes en Honduras, con personas naturales o jurídicas vinculadas o relacionadas en el extranjero.

Y la base para la determinación de los precios parte de lo que el principio de plena competencia "Arm's Length"; considerando para tales efectos, tanto los métodos tradicionales, como los no tradicionales que derivan de las directrices de OCDE para efecto de su aplicabilidad. 
La Ley No. 822, Ley de Concertación Tributaria (LCT), publicada en la Gaceta Diario Oficial No. 241 del 17 de diciembre del 2012 y en vigencia a partir del 1 de enero del 2013 creó y regula el Impuesto sobre la Renta (IR), Impuesto al Valor Agregado (IVA), Impuesto Selectivo al Consumo (ISC), Impuesto de Timbres Fiscales y demás regímenes especiales, conlleva (y por primera vez en la legislación tributaria nicaragüense) en su capítulo $\mathrm{V}$ del título l, que va del articulo 93 al artículo 106, la regulación sobre los precios de transferencias. Sin embargo de conformidad con el artículo 303, las disposiciones referidas a precios de transferencia, serán aplicables a partir del 1 de enero del 2016.

\section{COSTA RICA}

Con el objetivo de evitar la manipulación artificial de los precios de transferencia, la Presidencia de Costa Rica publicó en el diario oficial La Gaceta, el pasado 13 de septiembre de 2013, el nuevo Reglamento de precios de transferencia. Mediante el decreto ejecutivo número $37898-\mathrm{H}$ se establecen las reglas para valorar las transacciones de los contribuyentes con partes vinculadas locales o del exterior, con lo cual Costa Rica ya cuenta con reglas que regulan los precios de bienes y servicios pactados entre empresas relacionadas, que ya se encuentran vigentes, cuya documentación deberá estar disponible con la declaración de 2015.

\section{PRINCIPIOS DE MERCADO}

\section{EL SALVADOR}

Según lo establecido en el Artículo 62-A del Código Tributario, en cuanto a determinación del precio dice lo siguiente: "Para efectos tributarios, los contribuyentes que celebren operaciones o transacciones con sujetos relacionados, estarán obligados a determinar los precios y montos de las contraprestaciones, considerando para esas operaciones los precios de mercado utilizados en transferencias de bienes o prestación de servicios de la misma especie, entre sujetos independientes. Igualmente los contribuyentes deberán determinar a precios de mercado las operaciones o transacciones que se celebren con sujetos domiciliados, constituidos o ubicados en países, estados o territorios con regímenes fiscales preferentes, de baja o nula tributación o paraísos fiscales".

\section{PANAMA}

El Artículo 762-A del Código Fiscal establece que: "El principio de libre competencia. Las operaciones que realicen los contribuyentes con partes relacionadas deberán valorarse de acuerdo con el principio de libre competencia, es decir, los ingresos ordinarios y extraordinarios y los costos y deducciones necesarios para realizar esas operaciones deberán determinarse considerando el precio o monto que habrían acordado partes independientes bajo circunstancias similares en condiciones de libre competencia. El valor así determinado deberá reflejarse para fines fiscales en las declaraciones de rentas que presente el contribuyente, siguiendo para ello la metodología establecida en los artículos contenidos en este capítulo."

\section{GUATEMALA}

Tal a lo mencionado en el apartado anterior, el artículo 57 de la Ley de ISR establece que "se entiende para efectos tributarios, por principio de libre competencia, el precio o monto para una operación determinada que habrían acordado partes independientes en operaciones comparables a las realizadas en condiciones de libre competencia. El contribuyente debe consignar el valor así determinado en sus libros y registros contables, cuando se trate de operaciones con partes relacionadas y la diferencia debe integrarse en la renta imponible".

\section{HONDURAS}

De acuerdo a lo establecido en el Artículo 5, de la Ley de Regulación de Precios de Transferencia, los contribuyentes se obligan a lo siguiente: "Los contribuyentes de Impuesto sobre la renta que sean partes relacionadas y que realicen operaciones comerciales y financieras entre sí, están obligados a determinar para efectos fiscales, sus ingresos, costos y deducciones, aplicando para dichas operaciones resultados operativos, precios y márgenes de utilidad que se hubieren utilizado en operaciones comerciales y financieras comparables entre partes independientes". 


\section{NICARAGUA}

De acuerdo a lo establecido en el Art. 47, de la Ley 822 de Concertación Tributaria y sus reformas, se deberá tener en cuenta lo siguiente: "La valoración de las operaciones que se realicen entre partes relacionadas, se encuentran reguladas en el Capítulo V del Título I de esta Ley como parte normativa del IR de rentas de actividades económicas".

\section{COSTA RICA}

Según lo establece el artículo 1 del Decreto No. №37898-H, se deberá cumplir lo siguiente: "Los contribuyentes que celebren operaciones con partes vinculadas, están obligados, para efectos del impuesto sobre la renta, a determinar sus ingresos, costos y deducciones considerando para esas operaciones los precios y montos de contraprestaciones, que pactarían entre personas o entidades independientes en operaciones comparables, atendiendo al principio de libre competencia, conforme al principio de realidad económica contenido en el artículo $8^{\circ}$ del Código de Normas y Procedimientos Tributarios".

\section{SUJETOS RELACIONADOS}

\section{EL SALVADOR}

Según el Artículo 199-C del Código Tributario, para efectos de lo dispuesto en este Código y demás leyes tributarias se entenderá como sujetos relacionados:

a) Cuando uno de ellos dirija o controle la otra, o posea, directa o indirectamente, al menos el $25 \%$ de su capital social o de sus derechos de voto.

b) Cuando cinco o menos personas dirijan o controlen ambas personas, o posean en su conjunto, directa o indirectamente, al menos el $25 \%$ de participación en el capital social o los derechos de voto de ambas personas.

c) Cuando sean sociedades que pertenezcan a una misma unidad de decisión o grupo empresarial.

En particular, dos sociedades forman parte de la misma unidad de decisión o grupo empresarial si una de ellas es socio o partícipe de la otra y se encuentra en relación con ésta en alguna de las siguientes situaciones:

i. Posea la mayoría de los derechos de voto.

ii. Tenga la facultad de nombrar o destituir a la mayoría de los miembros del órgano de administración.

iii. Pueda disponer, en virtud de acuerdos celebrados con otros socios, de la mayoría de los derechos de voto.

iv. Haya designado exclusivamente con sus votos a la mayoría de los miembros del órgano de administración.

v. La mayoría de los miembros del órgano de administración de la sociedad dominada sean miembros o gerentes del órgano de administración de la sociedad dominante o de otra dominada por ésta.

Cuando dos sociedades formen parte cada una de ellas de una unidad de decisión o grupo empresarial respecto de una tercera sociedad, de acuerdo con lo dispuesto en este literal, todas estas sociedades integrarán una unidad de decisión o grupo empresarial.

d) A los efectos de los literales anteriores, también se considera que una persona natural posee una participación en el capital social o derechos de voto, cuando la titularidad de la participación directa o indirectamente, corresponde al cónyuge o persona unida por relación de parentesco en línea directa o colateral, por consanguinidad hasta el cuarto grado o por afinidad hasta el segundo grado.

e) En una unión de personas, sociedad de hecho o contrato de colaboración empresarial o un contrato de asociación en participación, cuando alguno de los contratantes o asociados participe directa o indirectamente en más del $25 \%$ por ciento en el resultado o utilidad del contrato o de las actividades derivadas de la asociación.

f) Una persona domiciliada en el país y un distribuidor o ente exclusivo de la misma residente en el extranjero.

g) Un distribuidor o agente exclusivo domiciliado en el país de una entidad domiciliada en el exterior y ésta última.

h) Una persona domiciliada en el país y su proveedor del exterior, cuando éste le efectué compras, y el volumen representa más del cincuenta por ciento (50\%).

i) Una persona residente en el país y sus establecimientos permanentes en el extranjero.

j) Un establecimiento permanente situado en el país y su casa central o matriz residente en el exterior, otro establecimiento permanente de la misma o una persona con ella relacionada. 
El Artículo 762-C del Código Fiscal, establece la definición de partes relacionadas de la siguiente manera: "A efectos de este Capítulo, dos o más personas se considerarán partes relacionadas cuando una de ellas participe de manera directa o indirecta en la administración, control o capital de la otra, o cuando una persona o grupo de personas participe directa o indirectamente en la administración, control o capital de dichas personas.

Asimismo, se consideran partes relacionadas de un establecimiento permanente, la oficina principal u otros establecimientos permanentes de la misma, así como las personas señaladas en el párrafo anterior y sus establecimientos permanentes.

Como establecimiento permanente entiéndase la definición contenida en el artículo 762-M de este Capítulo, o, según el país que se trate, en el texto de los tratados o convenios para evitar la doble tributación internacional celebrados por la República de Panamá."

\section{GUATEMALA}

De acuerdo al Artículo 38 del Acuerdo Gubernativo 213-2013, se considera partes relacionadas: "A los efectos de lo dispuestos en los artículos 56 y 57 de la Ley, una persona residente en Guatemala se considera relacionada con una residente en el extranjero cuando ambas estén unidas en sus relaciones comerciales, financieras o de servicios, por condiciones aceptadas o impuestas que difieran de las que serían acordadas por personas independientes y que se encuentran dentro de los supuestos que la norma legal establece para considerarlas vinculadas o relacionadas. Conforme a lo dispuesto en el artículo 56 de la Ley, dirigir o controlar es el poder de influir o determinar las decisiones clave de otra persona.

Asimismo, una persona posee indirectamente una participación en el capital de otra, cuando posee una participación en el capital de una entidad, que a su vez posee una de esa otra."

\section{HONDURAS}

El Artículo 3, numeral 3) de la Ley de Regulación de Precios de Transferencia, establece el concepto de "Partes relacionadas o Vinculadas", lo siguiente: "para efectos fiscales, se considerara que dos o más personas naturales o jurídicas domiciliadas o no, son partes relacionadas, cuando:

a) Una persona natural o jurídica participe directa o indirectamente en la dirección, control o en el capital de otra debidamente documentado o legalizado;

b) Unas mismas personas naturales o jurídicas participen directa o indirectamente en la dirección, control o en el capital de otra debidamente documentado y legalizado;

c) Sean sociedades que constituyan individualmente una unidad de decisión, donde una sociedad es socia de otra de conformidad a lo establecido en el Artículo 4 de la presente Ley y se encuentra en relación con esta en alguna de las siguientes situaciones: i) Posea la mayoría de los derechos de voto. Tenga la facultad de nombrar o destituir a la mayoría de los miembros del órgano de administración; ii) Pueda disponer, en virtud de acuerdos celebrados con otros socios, de la mayoría de los derechos de voto; y iii) Haya designado exclusivamente con sus votos a la mayoría de los miembros del órgano de administración;

d) Se realicen operaciones comerciales y financieras directas o indirectas, entendiéndose como indirectas aquellas que tengan por objeto reducir la base gravable del Impuesto sobre la Renta, entre sujetos pasivos residentes o domiciliados en el territorio nacional y personas ubicadas en otra jurisdicción califica como paraíso fiscal.

e) Una persona natural o jurídica residente en el país tiene establecimientos permanentes en el exterior, y,

f) Se trate de una sociedad relacionada con otra con los mismos consejeros o administradores." 
Según lo menciona el Artículo 94 de la Ley 822 de Concertación Tributaria y sus reformas se entenderá por Partes relacionadas, lo siguiente:

1. A los efectos de esta ley, dos personas se consideran partes relacionadas:

a. Cuando una de ellas dirija o controle a la otra, o posea, directa o indirectamente, al menos el cuarenta por ciento (40\%) de su capital social o de sus derechos de voto;

b. Cuando cinco o menos personas dirijan o controlen a estas dos personas, o posean en su conjunto, directa o indirectamente, al menos el cuarenta por ciento (40\%) de participación en el capital social o los derechos de voto de ambas personas; $y$

c. Cuando sean sociedades que pertenezcan a una misma unidad de decisión. Se entenderá que, dos sociedades forman parte de la misma unidad de decisión si una de ellas es socio o partícipe de la otra y se encuentra en relación con ésta en alguna de las siguientes situaciones:

i. Posea la mayoría de los derechos de voto;

ii. Tenga la facultad de nombrar o destituir a la mayoría de los miembros del órgano de administración;

iii. Pueda disponer, en virtud de acuerdos celebrados con otros socios, de la mayoría de los derechos de voto;

iv. Haya designado exclusivamente con sus votos a la mayoría de los miembros del órgano de administración; y

v. La mayoría de los miembros del órgano de administración dela sociedad dominada sean miembros del órgano de administración o altos directivos de la sociedad dominante o de otra dominada por ésta. Cuando dos sociedades formen parte cada una de ellas de una unidad de decisión respecto de una tercera sociedad de acuerdo con lo dispuesto en este literal "c", todas estas sociedades integrarán una unidad de decisión.

2. A los efectos del numeral 1, también se considera que una persona física posee una participación en el capital social o derechos de voto cuando la titularidad de la participación, directa o indirectamente, corresponde al cónyuge o persona unida por relación de parentesco, en línea directa o colateral, por consanguinidad hasta el cuarto grado o por afinidad hasta el segundo grado.

3. También se considerarán partes relacionadas:

a. En un contrato de colaboración empresarial o un contrato de asociación en participación cuando alguno de los contratantes o asociados participe directa o indirectamente en más del cuarenta por ciento (40\%) en el resultado o utilidad del contrato o de las actividades derivadas de la asociación;

b. Una persona residente en el país y un distribuidor o agente exclusivo de la misma residente en el extranjero;

c. Un distribuidor o agente exclusivo residente en el país de una entidad residente en el exterior y esta última;

d. Una persona residente en el país y sus establecimientos permanentes en el extranjero; y

e. Un establecimiento permanente situado en el país y su casa matriz residente en el exterior u otro establecimiento permanente de la misma o una persona con ella relacionada.

\section{COSTA RICA}

De acuerdo a lo establecido en el Artículo 4, del Reglamento de Precios de Transferencia, la Definición de partes vinculadas. Se detalla así: "A los efectos del presente Decreto, se consideran partes vinculadas las personas físicas o jurídicas y demás entidades residentes en Costa Rica y aquellas también residentes en el exterior, que participen directa o indirectamente en la dirección, control o capital del contribuyente, o cuando las mismas personas participen directa o indirectamente en la dirección, control o capital de ambos contribuyentes, o que por alguna otra causa objetiva pueda ejercer una influencia sistemática en sus decisiones de precio.

Se presume que existe vinculación, en los términos de la Ley del Impuesto sobre la renta, cuando una persona o entidad tenga su residencia en una jurisdicción extraterritorial que no tenga facultades suficientes, según la legislación de ese país, para intercambiar información de relevancia fiscal con la administración tributaria costarricense.

Se considerarán específicamente partes vinculadas:

1. Las personas físicas o jurídicas que califiquen en alguna de las siguientes situaciones:

a) Una de ellas dirija o controle la otra o posea, directa o indirectamente, al menos el $25 \%$ de su capital social o de sus derechos a voto.

b) Cuando cinco o menos personas dirijan o controlen ambas personas jurídicas, o posean en su conjunto, directa o indirectamente, al menos el $25 \%$ de participación en el capital social o los derechos a voto de ambas personas.

c) Cuando se trate de personas jurídicas que constituyan una misma unidad de decisión. En particular, se presumirá que existe unidad de decisión cuando una persona jurídica sea socia o partícipe de otra y se encuentre en relación con ésta en alguna de las siguientes situaciones:

i. Que posea la mayoría de derechos de voto.

ii. Que tenga facultad de nombrar o destituir a la mayoría de los miembros del órgano de administración.

iii. Que pueda disponer, en virtud de acuerdos celebrados con otros socios, de la mayoría de los derechos de voto.

iv. Que haya designado exclusivamente con sus votos a la mayoría del órgano de administración.

v. Que la mayoría de los miembros del órgano de administración de la persona jurídica dominada, sean miembros del órgano de administración o altos ejecutivos de la persona jurídica dominante o de otra dominada por esta. 


\section{COSTA RICA}

d) Cuando dos o más personas jurídicas formen cada una de ellas, una unidad de decisión respecto de una tercera persona jurídica, de acuerdo con lo dispuesto en este apartado, todas ellas integrarán una unidad de decisión.

A los efectos de este apartado, también se considera que una persona física posee una participación en el capital social o derechos de voto, cuando la titularidad de la participación, directa o indirectamente, corresponde al cónyuge o persona unida por relación de parentesco, en línea directa o colateral, por consanguinidad hasta el cuarto grado o por afinidad hasta el segundo grado.

2. También se considerarán partes relacionadas:

a) En un contrato de colaboración empresarial o un contrato de asociación en participación, cuando alguno de los contratantes o asociados participe directa o indirectamente en más del $25 \%$ en el resultado o utilidad del contrato o de las actividades derivadas de la asociación.

b) Una persona residente en el país y un distribuidor o agente exclusivo de la misma, residente en el exterior.

c) Un distribuidor o agente exclusivo residente en el país de una entidad residente en el exterior y esta última.

d) Una persona residente en el país y sus establecimientos permanentes en el exterior.

e) Un establecimiento permanente situado en el país y su casa matriz residente en el exterior, otro establecimiento permanente de la misma o una persona con ella relacionada."

\section{METODOS VIGENTES}

\section{EL SALVADOR}

Los métodos vigentes en El Salvador de acuerdo a lo establecido en la Guía de Orientación para la documentación de precios de transferencia emitida el 23 de marzo de 2012, que ratifica los métodos siguientes:

1. Método de precio comparable no controlado.

2. Método de precio de reventa.

3. Método de costo adicionado.

4. Método de partición de utilidades.

5. Método residual de parti ción de utilidades.

6. Método de márgenes transaccionales de utilidad de operación.

\section{PANAMA}

De acuerdo al código fiscal y su artículo 762-F, como parte de la reforma de la Ley 33, establece los métodos siguientes: 1. Método de precio comparable no controlado.

2. Método de costo adicionado.

3. Método de precio de reventa.

4. Método de la partición de utilidades.

5. Método de margen neto de la transacción.

\section{GUATEMALA}

El Decreto 10-2012 y 213-2013 establece seis métodos para determinar que el precio cumple con el principio de libre competencia, como se detallan a continuación

1. Método del precio comparable no controlado

2. Método de costo adicionado

3. Método del precio de reventa

4. Método de la partición de utilidades

5. Método del margen neto de la transacción

6 . Método de valoración para importaciones y exportaciones de mercancías

\section{HONDURAS}

De acuerdo al Artículo 8 de la Ley Reguladora de Precios de Transferencia, se detallan los siguientes métodos:

1. Método de Precio Comparable no Controlado.

2. Método de Precio de Reventa.

3. Método de Costo Adicionado.

4. Método de distribución de utilidades.

5. Método de margen neto de la transacción. 


\section{NICARAGUA}

Según lo establece el artículo 100 de la Ley 822 de Concertación Tributaria y sus reformas, se mencionan los siguientes métodos:

1. Método del precio comparable no controlado

2. Método del costo adicionado

3. Método del precio de reventa

4. Método de la partición de utilidades

5. Método del margen neto de la transacción

\section{COSTA RICA}

De acuerdo al artículo 6 de la reforma del Código de Normas y Procedimientos, en fecha septiembre 2013, establece los siguientes métodos:

1. Método del precio comparable no controlado.

2. Método del costo adicionado

3. Método del precio de reventa

4. Método de la partición de utilidades

5. Método del margen neto de la transacción

\section{REQUISITOS DE DOCUMENTACION}

\section{EL SALVADOR}

Como parte de los requisitos informativos el artículo 124-A del Código Tributario establece que debe presentarse el formulario de Sujetos relacionados (31 de mayo): "Los contribuyentes que celebren operaciones con sujetos relacionados o sujetos domiciliados, constituidos o ubicados en países, estados o territorios con regímenes fiscales preferentes, de baja o nula tributación o paraísos fiscales durante un ejercicio fiscal, y tales operaciones ya sea en forma individual o conjunta sean iguales o superiores a quinientos setenta y un mil cuatrocientos veintinueve dólares de los Estados Unidos de América $(\$ 571,429.00)$, deberán presentar un Informe de las operaciones que ejecute con dichos sujetos, a través de los formularios que proporcione la Administración Tributaria con los requisitos y especificaciones técnicas que ésta disponga para tal efecto."

\section{PANAMA}

Para dar cumplimiento a lo establecido en el artículo 762-I del Código Fiscal. Se debe presentar el formulario se debe presentar anualmente (30 de junio): "Los contribuyentes deben contar, al momento de presentar su declaración del Impuesto sobre la Renta, con la información y el análisis suficiente para valorar y documentar sus operaciones con partes relacionadas, de acuerdo con las disposiciones legales establecidas en este Capítulo. No obstante, el contribuyente solo deberá aportar la documentación establecida en este Capítulo, a requerimiento de la Dirección General de Ingresos, dentro del plazo de cuarenta y cinco días desde la recepción del requerimiento".

\section{GUATEMALA}

El artículo 68 del Ley de ISR establece que es un requisito en relación a la presentación de la declaración de Impuesto sobre la renta corporativa, la documentación relativa a las operaciones con sujetos relacionados, según el detalle siguiente (31 de marzo):

"Los contribuyentes deben tener, al momento de presentar la declaración jurada del Impuesto Sobre la Renta, la información y el análisis suficiente para demostrar y justificar la correcta determinación de los precios, los montos de las contraprestaciones los márgenes de ganancia en sus operaciones con partes relacionadas, de acuerdo con las disposiciones de esta ley". 


\section{HONDURAS}

De acuerdo a lo establecido en el artículo 17 de la Ley de Regulación de Precios de Transferencia (30 de abril): "Para efectos de esta Ley, los contribuyentes deberán presentar a la Dirección Ejecutiva de Ingresos, la declaración de Impuestos, la información y el análisis suficientes para valorar sus operaciones con partes relacionadas, dicha obligación se establecerá sin perjuicio de cualquier información adicional que se requiera a petición de la Dirección Ejecutiva de Ingresos".

\section{NICARAGUA}

Según lo establece el artículo 104 de la Ley 822 de Concertación Tributaria y sus reformas, se establece que (31 de marzo): "Los contribuyentes deben tener, al tiempo de presentar la declaración del Impuesto, la información y el análisis suficiente para valorar sus operaciones con partes relacionadas, de acuerdo con las disposiciones de esta Ley".

\section{COSTA RICA}

De acuerdo al artículo 8 y 9 de la reforma del Código de Normas y Procedimientos (15 de diciembre): "Están obligados a presentar ante la Dirección General de Tributación la declaración informativa de precios de transferencia, con periodicidad anual, aquellos contribuyentes que se encuentren dentro de las dos situaciones siguientes:

a. Que realicen operaciones nacionales o transfronterizas con empresas vinculada y

b. Se encuentren clasificados como grandes contribuyentes o grandes empresas territoriales, o que sean personas o entidades que se encuentren bajo el régimen de zona franca".

Y, "Los contribuyentes deben tener la información, los documentos y el análisis suficiente para valorar sus operaciones con partes vinculadas, según lo defina la Administración Tributaria mediante resolución general. La documentación elaborada o utilizada en este proceso, debe estar a disposición de la Administración Tributaria, con el fin de comprobar el cumplimiento del principio de plena competencia".

\section{MARCO SANCIONATORIO}

\section{EL SALVADOR}

De acuerdo con el Código Tributario, no existe una multa específica por no contar con la documentación que demuestre el cumplimiento del principio de valor de mercado por las transacciones intercompañía. No obstante de acuerdo al Artículo 238 del Código Tributario, la DGII puede aplicar multas del 20 por ciento de las infracciones que originen omisión en el pago de contribuciones como por ejemplo, cuando los precios de transferencia de contribuyentes salvadoreños no sean consistentes con el principio de valor de mercado, de acuerdo con las regulaciones en precios de transferencia detalladas en el CT, ya sea por que la operación origina un gasto en exceso o por que permite subvaluar los ingresos percibidos.

\section{PANAMA}

De acuerdo al Código Fiscal, no existe una multa específica por no contar con la documentación que demuestre el cumplimiento del principio de valor de mercado. Sin embargo, con la nueva legislación, los contribuyentes afectados están en la obligación de presentar un Informe de Precios de Transferencia anual, según lo estipulado en el artículo 762-I del Código Fiscal, dentro de los seis (6) meses siguientes a la fecha de cierre del período fiscal correspondiente. En caso de no presentar este informe el contribuyente será sancionado con una multa equivalente al $1 \%$ del monto bruto total de las operaciones efectuadas con partes relacionadas.

\section{GUATEMALA}

De acuerdo a la Ley de Impuesto sobre la Renta, no existe una multa específica por no contar con la documentación que demuestre el cumplimiento del principio de valor de mercado, En tal sentido, el artículo 88 del Código Tributario permite que la SAT aplique multas por la omisión en el pago de los tributos y hace referencia a la sanción en el Art. 89 del referido Código, con una multa del $100 \%$ ciento de las infracciones que originen omisión en el pago de contribuciones como por ejemplo, cuando los precios de transferencia de contribuyentes guatemaltecos no sean consistentes con el principio de valor de mercado, de acuerdo con las regulaciones en precios de transferencia detalladas en la Ley de Impuesto sobre la Renta, ya sea porque la operación origina un gasto en exceso o porque permite subvaluar los ingresos percibidos. 
De acuerdo al Artículo 18 y 19 de la Ley Reguladora de Precios de Transferencia respectivamente, se consisten infracciones lo siguiente:

1. "No aportar, o aportar con datos falsos o manifiestamente incompletos o inexactos la información o documentación que en su momento se exija por la administración tributaria;

2. Declarar en cualquier ejercicio una base imponible inferior a la que hubiera correspondido debido a una valoración convenida distinta de la que habrían acordado en circunstancias comparables partes independientes, salvo que exista documentación que compruebe o justifique la veracidad de lo declarado.

3. Cualquier otros incumplimiento a las disposiciones contenida en la Ley".

La infracción descrita en el numeral 1 será sancionada con US\$10,000, pagaderos en su equivalente a lempiras.

La Infracción descrita en el numeral 2 será sancionada con un 15\% sobre el importe del ajuste realizado por la administración, en el caso que la conducta se acompañara de lo mencionado en el numeral 1, la sanción se elevará a un $30 \%$ o US $\$ 20,000$, pagaderos en lempiras, la que fuere mayor.

\section{NICARAGUA}

De acuerdo al Código Fiscal, no existe una multa específica por no contar con la documentación que demuestre el cumplimiento del principio de valor de mercado. Sin embargo, de acuerdo Artículo 134 inciso tercero del Código Tributario, se establece que: "la declaración incompleta o errónea, la omisión de balances o documentos anexos a la declaración o la presentación incompleta de éstos que puedan inducir a la liquidación de un impuesto inferior al que corresponda, será sancionada administrativamente aplicando lo dispuesto en el artículo 127, numeral 3 del presente Código, a menos que el contribuyente pruebe haber empleado la debida diligencia y haber actuado de buena fe".

De acuerdo al artículo 127 numeral 3 del referido Código, la multa al incumplimiento formal corresponde al una sanción pecuniaria de entre un mínimo de SETENTA a un máximo de NOVENTA UNIDADES DE MULTA, por cada día que impida las inspecciones o verificaciones, por su no comparecencia o atraso en el suministro de información,

Y una multa al incumplimiento sustantivo, se establece en el artículo 135 numeral b. del Código Tributario de acuerdo a lo siguiente: "La omisión, la presentación tardía de declaración, o la presentación de declaración con información incompleta o errónea, faculta a la Administración Tributaria de manera consolidada a: Tasarle de oficio al contribuyente lo que se calcule debería pagar y declararles incursos en una multa equivalente al veinticinco por ciento del impuesto así tasado de oficio".

\section{COSTA RICA}

De acuerdo a lo establecido en el Código de Normas y Procedimientos no existe una multa especifica por no contar con la documentación que demuestre el cumplimiento del principio de valor de mercado, sin embargo de acuerdo a lo que establece el artículo 83 del Código de Normas y Procedimientos Tributarios existe una sanción por no presentación de la declaración informativa: a quienes incumplan la obligación de presentar la declaración informativa, estando obligado a ello, habrá lugar a la imposición de una sanción equivalente a una multa pecuniaria proporcional del dos por ciento (2\%) de la cifra de ingresos brutos del sujeto infractor, en el período el impuesto sobre las utilidades, anterior a aquel en que se produjo la infracción, con un mínimo de diez salarios base y un máximo de cien salarios base.

Además, el artículo 81 numeral 1, literal b.i), menciona que: Infracciones materiales por omisión, inexactitud, o por solicitud improcedente de compensación o devolución, o por obtención de devoluciones improcedentes constituyen infracciones tributarias: "El empleo de datos falsos, incompletos o inexactos, de los cuales se derive un menor impuesto o un saldo menor por pagar o un mayor saldo a favor del contribuyente o responsable".

La sanción corresponde una multa pecuniaria del cincuenta por ciento (50\%) sobre la base de la sanción que corresponda.

\section{Bibliografía}

Ministerio de Hacienda, Código Tributario de la República de El Salvador, 2016.

Ministerio de Finanzas Publicas, Código Tributario de la República de Guatemala, 2017.

Ministerio de Hacienda y Crédito Publico, Código Tributario de la República de Nicaragua, 2018.

Ministerio de Hacienda, Código Tributario de la República de Costa Rica, 2016.

Secretaria de Finanzas, Código Tributario de la República de Honduras, 2017.

Ministerio de Economía y Finanzas, Código Fiscal de la República de Panamá , 2016. 